\title{
The nursing workload assessed through the Nursing Activities Score as a predictor for the occurrence of ventilator-associated pneumonia in an adult intensive care unit
}

Fabiola Alves Gomes ${ }^{1,2}$, Denise Von Dolinger de Brito Röder ${ }^{2,3}$, Thúlio Marquez Cunha ${ }^{2,4}$, Rosângela de Oliveira Felice $^{2,4}$, Guilherme Silva Mendonça ${ }^{2,4}$, Clesnan Mendes-Rodrigues ${ }^{* 1}$

${ }^{1}$ Nursing, Medicine Faculty, Federal University of Uberlândia, Uberlândia, Brazil

${ }^{2}$ Post-graduation Program in Health Sciences, Federal University of Uberlândia. Uberlândia, Minas Gerais, Brazil

${ }^{3}$ Institute of Biomedical Sciences, Federal University of Uberlândia, Uberlândia, Brazil

${ }^{4}$ Medicine, Medicine Faculty, Federal University of Uberlândia, Uberlândia, Brazil

${ }^{5}$ Clinical Hospital of Uberlândia, Federal University of Uberlândia, Uberlândia, Brazil

Received: February 14, 2019

DOI: $10.5430 /$ jnep.v9n9p104
Accepted: June 5, 2019

Online Published: June 25, 2019

\begin{abstract}
Objective: Evaluate the relation of nursing workload, evaluated by the Nursing Activities Score (NAS), with the occurrence of Ventilator-associated Pneumonia (VAP) in an Intensive Care Unit (ICU) and the impact of VAP on hospitalization costs.

Methods: Retrospective cohort study in Adult ICU of a high complexity Brazilian university hospital. The profile, outcomes, costs, and daily NAS from patients were collected. We also proposed some workload indicators based on NAS daily evaluation. Results: The study included 195 patients, $27.17 \%$ diagnosed with VAP. VAP was more prevalent in patients diagnosed with trauma on admission. The total costs of care were higher for VAP patients. In all multivariate models tested were predictive for VAP: the patient's intubation that occurs in days prior of the ICU admission day (higher risk if occurs in days prior the ICU admission day) and ventilation time prior ICU (higher risk if higher time). We found others predictors, but these were dependent on the model tested. Additional risk predictors were tracheostomy, propofol use, neuromuscular blocker use and the higher NAS from admission. The protective factors found were the percentage of adequacy of the assignment based in NAS that measure if the workload measured by the NAS was offered and the increment in NAS during the ventilation time.

Conclusions: The offering of an adequate nursing work scale (adequate number of professionals for the care), as a function of the nursing workload measured by the NAS, could be effective in the reduction of VAP, hospital stay time and hospital costs.
\end{abstract}

Key Words: Healthcare-associated infections, Hospital costs, Risk factors, Sizing, Nursing staff

\section{INTRODUCTION}

Ventilator-associated pneumonia (VAP) is defined as the infection that begins after 48-72 hours of endotracheal intu- bation and invasive mechanical ventilation, being the most common healthcare-associated infection (HAI) in intensive care unit (ICU), with a prevalence varying from $24 \%$ to $50 \%$

\footnotetext{
*Correspondence: Clesnan Mendes-Rodrigues; Email: clesnan@hotmail.com; Address: Enfermagem, Faculdade de Medicina, Universidade Federal de Uberlândia, Uberlândia, Av. Pará 1720, CEP 38402-902, Brazil. 
and overall mortality of $13 \% .^{[1-6]}$ It is, therefore, a serious complication that may have an impact on the length of stay and hospital costs. The increase in the incidence of this HAI, according to several authors, is related to the inadequate number of nursing professionals who provide the minimum necessary assistance to the patient. ${ }^{[7-12]}$

The ICU hospitalization can represent up to $30 \%$ of hospital budget costs, with human resources accounting for a large share of these costs. ${ }^{[13]}$ In this context, it is very important to determine the adequate proportion of nursing professionals per patient and the fundamental workload to optimize outcomes related to the promotion of patients' health. This would also improve the financial management of hospitals. However, if staffing is inadequate to meet patient care needs, these costs may be even greater as a result of the increase in the number of cases of HAI's and other adverse events. ${ }^{[14,15}$

With the objective of determining the correct staffing, which addresses the number of nursing professionals per patient per day, some instruments have been used to estimate nursing workload, providing information so as to dimension the team in an economically efficient way, but ensuring safe patient care. One of these tools used in ICUs is the Nursing Activities Score (NAS), based on the real-time assessment of the duration of nursing activities as well as the analysis of the use of resources and nursing interventions to predict the workload to be dispensed by nursing staff for each patient during one day. ${ }^{[15,16]}$ The NAS does not regard the severity of the patients' illnesses or their profiles.

Thus, the present study aims to evaluate the relation between the nursing workload measured through the Nursing Activities Score and the occurrence of ventilator-associated pneumonia, and its influence on hospitalization costs in an adult intensive care unit.

\section{MethodS}

\subsection{Type of study, location and ethical considerations}

This is a retrospective cohort study conducted in a nonspecialized Adult ICU of a highly complex Brazilian university hospital with 525 beds, of which 30 beds are in the non-specialized Adult ICU evaluated here. The "Hospital de Clínicas de Uberlândia" is located in Uberlândia, Minas Gerais state, Brazil. Data were obtained from the medical records of patients hospitalized in the Adult ICU from January to June 2014, period in which the NAS was evaluated daily for all patients in the unit. Patients necessarily met two inclusion criteria: patients older than 18 years and who underwent mechanical ventilation for more than 48 hours during the stay in the ICU.

The study was conducted in accordance with Brazilian ResPublished by Sciedu Press olution 466 of 2012 of the National Health Council ${ }^{[20]}$ and in accordance with the ethical principles of the Declaration of Helsinki for medical research involving humans. It was submitted and approved by the Ethics and Research Committee of the Federal University of Uberlândia (number: CAAE: 43409414.8.0000.5152).

\subsection{VAP and patients data collection procedures}

The diagnosis of VAP was based on the criteria established by the American Thoracic Society and Infectious Diseases Society of America, which include: mechanical ventilation for a time equal to or greater than 48 hours; chest $\mathrm{x}$-ray with new or progressive pulmonary infiltrate associated with at least two clinical or laboratory abnormalities, including leukocytosis $\left(>10,000 \mathrm{~mm}^{3}\right)$ or leukopenia $\left(<4,000 \mathrm{~mm}^{3}\right)$; change in appearance of tracheal secretion; ventilatory worsening identified through the evaluation of the $\mathrm{PaO}_{2} / \mathrm{FiO}_{2}$ relation; fever $\left(>38^{\circ} \mathrm{C}\right)$ or hypothermia $\left(<35^{\circ} \mathrm{C}\right)$; and auscultation compatible with airspace consolidation. The period prior to the suspicion of VAP was always used as a reference. ${ }^{[17]}$ The diagnosis of VAP was confirmed by the medical team responsible for the study, who reassessed all the x-rays and carefully checked the clinical and laboratory information contained in the medical records for the diagnosis of all patients.

The data collected for each patient on the day of admission in the ICU (first 24 hours) was: age; gender; admission diagnosis (categorized in clinical, trauma, surgical and neurological); presence of invasive blood pressure, presence de delayed bladder cateterism, mean arterial pressure, presence of coagulopathy, pneumothorax. For all patients, the intubation was evaluated if it occurred on the day of admission in the ICU or before. In the ICU stay, the invasive procedures evaluated were: use of antibiotics; use of neuromuscular blockers and corticosteroids; length of stay before ICU admission, length of ICU stay; time of mechanical ventilation (prior to ICU and in ICU); if medication was used for sedation and analgesia; results of laboratory tests; results of cultures, the antibiogram and also the therapy adopted; Acute Physiology and Chronic Health Evaluation (APACHE II), Simplified Acute Physiology Score 3 (SAPS 3). For each patient we collected the hospitalization costs, considering the amount paid by the Brazilian Public Health System for the entire hospital stay. That was transformed in US\$ based on the exchange rate of the day of discharge from the hospital.

\subsection{Nursing Activities Score measurements}

The NAS ${ }^{[15]}$ was evaluated at all days of ICU stay for all patients. As the NAS was obtained from medical records and patient forms it was not possible to obtain the values of each sub-item of the NAS. We considered the day of VAP 
diagnosis as the event of interest and, for the other patients, a NAS median of 56.80 (mean $=58.85$ ), there is a deficit two days after extubation (which represents the period of VAP risk). Form the daily NAS, we obtained some derived measurements that describe the Nursing Workload in the ICU during the hospitalization (see Table 1). We also measured the number of hours of nursing in the work schedule during the period of interest to calculate the percentage of adequacy of said schedule. The nursing team that attends of $28.86 \%$ in the nursing staff with a dependency on 3.06 nursing professionals per month per bed. ${ }^{[18,19]}$ Normally the ratio of nursing staff to patients in the hospital studied here is one professional to each two patients as proposed by Brazilian legislation. During the study, we accompany this scale of work, but this ratio is altered very eventually by the low sizing of staff of the institution, as presented previously. in the ICU has 85 nursing technicians and 25 nurses, with

Table 1. Nursing workload measurements calculated from daily NAS

\begin{tabular}{|c|c|c|}
\hline Abbreviation & Indicator name & Description \\
\hline NAS-ad & NAS from admission & Refers to the first day of NAS evaluation in the ICU. Unit: points. \\
\hline NAS-a & NAS amplitude & $\begin{array}{l}\text { The NAS amplitude until the event of interest in the ICU, obtained by subtracting the } \\
\text { maximum NAS from the minimum NAS. Unit: points. }\end{array}$ \\
\hline NAS-m & mean NAS & The mean NAS up to the event of interest. Unit: points. \\
\hline NAS-cv & $\begin{array}{l}\text { coefficient of variation } \\
\text { of NAS }\end{array}$ & $\begin{array}{l}\text { The coefficient of variation of NAS was calculated in the period of interest. Unit: \%, } \\
\text { percentage. }\end{array}$ \\
\hline NAS-i & NAS increment & $\begin{array}{l}\text { The NAS increment score was calculated by subtracting the maximum NAS } \\
\text { (obtained from the second day of hospitalization until to the event of interest) from } \\
\text { the NAS from admission. Unit: points. }\end{array}$ \\
\hline NAS-ri & NAS relative increment & $\begin{array}{l}\text { The NAS-ri was obtained by dividing the NAS-i by the admission NAS and } \\
\text { multiplied by } 100 \text {. Unit: \%, percentage. }\end{array}$ \\
\hline NAS- $\Delta$ & Delta NAS & $\begin{array}{l}\text { The delta NAS, measures the increase or decrease in the NAS score, which was } \\
\text { calculated by subtracting the NAS of the day of the event of interest from the } \\
\text { admission NAS. Positive values indicate an increase in workload and negatives } \\
\text { indicate a decrease in workload. Unit: points. }\end{array}$ \\
\hline NAS-r $\Delta$ & Relative Delta NAS & $\begin{array}{l}\text { Resulted from the division of the NAS- } \Delta \text { by the NAS from admission and multiplied } \\
\text { by } 100 \text {. Unit: } \% \text {, percentage. }\end{array}$ \\
\hline NAS-paas & $\begin{array}{l}\text { Percentage of adequacy } \\
\text { of the assignment scale }\end{array}$ & $\begin{array}{l}\text { The percentage of adequacy of the assignment scale was calculated as a function of } \\
\text { the workload predicted by the NAS and the number of hours of nursing offered to } \\
\text { each patient (number of nursing hours in the work schedule or assignment scale). } \\
\text { For this we calculated the number of hours of nursing attributed in the work schedule } \\
\text { during the period of interest named SNHWS (Sum of the nursing hours in work } \\
\text { schedule), that is, the sum of the number of hours of nursing care provided in the } \\
\text { ICU. Additionally, the workload was also predicted by the sum of the NAS in the } \\
\text { period of interest divided by } 100 \text { and multiplied by } 24 \text {. This predicted workload was } \\
\text { named PNHNAS (Predicted nursing hours by NAS). On the other hand, to evaluate } \\
\text { the Percentage of adequacy of the assignment scale based in NAS (NAS-paas), the } \\
\text { SNHWS was divided by PNHNAS and multiplied by } 100 \text {. Values smaller than } 100 \\
\text { indicate that the predicted workload was not offered, if values are greater than } 100 \text {, it } \\
\text { indicates that the workload predicted by the NAS was met in the assignment of the } \\
\text { schedules. Unit: \%, percentage. }\end{array}$ \\
\hline
\end{tabular}

\subsection{Statistical analysis}

To compare the data from the quantitative variables between patients with VAP and without VAP, continuous data from each group were tested for normality by the KolmogorovSmirnov Lilliefors test. As most data did not present normality (Gaussian distribution), the medians were compared by the unpaired Wilcoxon test. The association between pres- ence or absence of PAV with qualitative variables was tested with the Independence Chi-Square test with continuity correction (when expected frequencies were greater than five) or Fisher's Exact test (other cases). The significance of 5\% was adopted.

For the prediction of VAP occurrence, data from the pre- 
dictor variables were initially adjusted to univariate logistic regression models. For variable selection, we used the results of the univariate analysis from a reduced dataset (data and results not showed). We included all the predictor variables that had statistical significance for the estimated parameters ( $p \leq .100$ ). Based on this selection, we obtained these variables from all patients. We did not include variables where data were absent for any patient. Based on this previous analysis, the predictors were included in multivariate models with all variables. After the adjustments, the Odds Ratio was calculated with confidence interval of $95 \%$ (Odds Ratio adjusted). For the reduced models, the backward variable selection method was used, with exclusion criterion based on the probability of the Wald test $(p<.050)$.

Some multivariate models were tested. They are: Model 1 (full model based on all predictors from ICU stay); Model 2 (reduced model based on all predictors from ICU stay); Model 3 (full model based on all predictors present at patient admission in the ICU); Model 4 (reduced model based on all predictors present at patient admission in the ICU). The reduced models were proposed since in the clinical case conduction of the patients it is easier to focus on less variables.

\section{Results}

The study included 195 patients, the majority being male, with a mean age of about 52 years. For comparison, the patients were grouped into two groups: patients with and without diagnosis of VAP. Fifty-three patients (27.17\%) were diagnosed with VAP. There was no statistically significant difference between the groups with and without VAP in relation to gender $(p=.152)$, age $(p=.799)$, the APACHE severity scores $(p=.485)$ and SAPS $(p=.480)$, as well as the outcomes of discharge and death in the ICU $(p=1.000)$. A significant difference was observed in relation to the hospitalization diagnosis in admission, with the highest trauma diagnosis in the VAP group $(p=.049)$.

Table 2. Baseline characteristics of patients in mechanical ventilation of the adult ICU evaluated for VAP

\begin{tabular}{|c|c|c|c|}
\hline \multirow{2}{*}{ Trait } & \multicolumn{2}{|c|}{ Ventilator-Associated Pneumonia } & \multirow{2}{*}{$\begin{array}{l}\text { Statistics } \\
\chi^{2}(p)\end{array}$} \\
\hline & without $(n=142)$ & with $(n=53)$ & \\
\hline \multicolumn{4}{|l|}{ Gender $(\%, n)$} \\
\hline Male & $61.27(87)$ & $73.58(39)$ & $2.051(.152)$ \\
\hline Female & $38.73(55)$ & $26.42(14)$ & \\
\hline \multicolumn{4}{|c|}{ Diagnosis of hospitalization ( $\%$ yes, n) } \\
\hline Clinical & $40.85(56)$ & $35.85(17)$ & $0.221(.638)$ \\
\hline Surgical & $51.41(75)$ & $54.72(26)$ & $0.063(.802)$ \\
\hline Trauma & $16.20(23)$ & $30.19(16)$ & $3.888(.049)$ \\
\hline Neurological & $17.61(26)$ & $24.53(11)$ & $0.779(.377)$ \\
\hline \multicolumn{4}{|l|}{ ICU Outcomes $(\%, n)$} \\
\hline Discharge from ICU & $63.38(90)$ & $62.26(33)$ & $0.000(1.000)$ \\
\hline Death in ICU & $36.62(52)$ & $37.74(20)$ & \\
\hline Trait (unit) & \multicolumn{2}{|c|}{ Mean \pm Standard error (Median) } & $Z(p)$ \\
\hline Age (years) & $52.58 \pm 1.67(55)$ & $51.98 \pm 2.58(56)$ & $-0.254(.799)$ \\
\hline APACHE II (points) & $18.35 \pm 0.72(17)$ & $19.06 \pm 1.07(18)$ & $-0.698(.485)$ \\
\hline SAPS 3 (points) & $63.59 \pm 1.17(61)$ & $61.13 \pm 2.21(62)$ & $-0.706(.480)$ \\
\hline
\end{tabular}

Note. Z: $Z$ statistic based on the Mann-Whitney test; $X^{2}$ : Chi-square statistical based on the Chi-Square test; $p$ : probability. The patient may have more than one hospitalization diagnosis.

The patients with VAP diagnosis had more Rocuronium Bromide use $(7.55 \%$ versus $1.41 \%, p=.048)$, propofol use $(79.25 \%$ versus $52.82 \%, p<.001)$, tracheostomy presence $(71.7 \%$ versus $20.42 \%, p<.001)$, the intubation occurs in days prior of the day of admission in the ICU (96.23\% versus $36.62 \%, p<.001$ ), higher mean arterial pressures (median 90 versus $80, p=.029)$, higher time the ventilation prior to ICU admission (median 10 days versus 0 days, $p<.001$ ), higher total ventilation time (median 17 versus $8, p<.001$ ), higher ICU hospitalization time (median 28 days versus 14.5 days, $p<.001$ ), higher hospitalization time (median 41 days versus 27 days, $p<.001)$. For the other variables, no difference in the groups was detected (see Table 3 ).

The daily hospitalization cost was the same in the two groups $(p=.760)$. There was a statistically significant difference 
between the group with and without VAP in relation to total out VAP with median US\$ 9,160.38 ( $p=.005)$ (see Table hospitalization costs, being the total cost higher in the group 3 ). with VAP, median US\$11,951.27, versus the patients with-

Table 3. Univariate analysis of some measurements to predict the risk of VAP in an adult ICU

\begin{tabular}{|c|c|c|c|c|c|}
\hline \multirow{2}{*}{ Trait } & \multicolumn{2}{|l|}{ without VAP } & \multicolumn{2}{|l|}{ with VAP } & \multirow{2}{*}{$\chi^{2}(p)$} \\
\hline & No $(\%, n)$ & Yes $(\%, n)$ & No $(\%, n)$ & Yes $(\%, n)$ & \\
\hline Rocuronium Bromide use & $98.59(140)$ & $1.41(2)$ & $92.45(49)$ & $7.55(4)$ & $(.048)$ \\
\hline Presence of invasive blood pressure & $52.82(75)$ & $47.18(67)$ & $37.74(20)$ & $62.26(33)$ & $2.94(.087)$ \\
\hline Propofol use & $47.18(67)$ & $52.82(75)$ & $20.75(11)$ & $79.25(42)$ & $10.16(.001)$ \\
\hline Tracheostomy presence & $79.58(113)$ & 20.42 (29) & $28.30(15)$ & $71.70(38)$ & $42.74(<.001)$ \\
\hline $\begin{array}{l}\text { Presence of delayed bladder } \\
\text { catererism }\end{array}$ & $16.20(23)$ & $83.80(119)$ & $5.66(3)$ & $94.34(50)$ & $2.85(.091)$ \\
\hline Presence of coagulopathy & $84.51(120)$ & $15.49(22)$ & 73.58 (39) & $26.42(14)$ & $2.38(.123)$ \\
\hline Pneumothorax & $96.48(137)$ & $3.52(5)$ & $90.57(48)$ & $9.43(5)$ & $1.69(.193)$ \\
\hline Corticosteroid use & $66.20(94)$ & $33.80(48)$ & $52.83(28)$ & $47.17(25)$ & $2.40(.121)$ \\
\hline $\begin{array}{l}\text { Intubation occurs in days prior of the } \\
\text { day of admission in the ICU }\end{array}$ & $63.38(90)$ & $36.62(52)$ & $3.77(2)$ & $96.23(51)$ & $52.66(<.001)$ \\
\hline Trait & Mean \pm SE & R (Median) & Mean \pm SE & R (Median) & $Z(p)$ \\
\hline Mean arterial pressure (value) & $83.12 \pm 1.41$ & $40-130(80)$ & $88.03 \pm 2.12$ & $48-128(90)$ & $-2.18(.029)$ \\
\hline Adherence to oral hygiene (\%) & $73.69 \pm 2.5$ & $0-100(81.83)$ & $82.18 \pm 2.54$ & $0-100(85.71)$ & $-1.27(.204)$ \\
\hline Ventilation time prior ICU (day) & $1.54 \pm 0.28$ & $0-26(0)$ & $13.87 \pm 1.73$ & $0-59(10)$ & $-10.34(<.001)$ \\
\hline Ventilation time in ICU (day) & $9.16 \pm 0.67$ & $1-40(6)$ & $8.49 \pm 0.76$ & $1-29(7)$ & $-0.59(.554)$ \\
\hline Ventilation time (day) & $10.31 \pm 0.72$ & $2-40(8)$ & $22.36 \pm 1.99$ & $9-80(17)$ & $-6.74(<.001)$ \\
\hline Time prior ICU (day) & $18.95 \pm 2.06$ & $0-164(11)$ & $16.17 \pm 3.41$ & $0-79(10)$ & $-0.04(.972)$ \\
\hline Time in ICU (day) & $18.1 \pm 1.17$ & $1-86(14.5)$ & $30.89 \pm 2.8$ & $10-89(28)$ & $-4.82(<.001)$ \\
\hline Time in hospital (day) & $37.05 \pm 2.46$ & $1-191(27)$ & $47.06 \pm 3.30$ & $15-117(41)$ & $-3.27(.001)$ \\
\hline Daily Cost (US\$) & $428.92 \pm 43.77$ & (325.39) & $332.35 \pm 23.53$ & (337.85) & $-0.305(.760)$ \\
\hline Total Cost (US\$) & $10,681.29 \pm 630.24$ & $(9,160.38)$ & $14,255.28 \pm 1,218.56$ & $(11,951.27)$ & $-0.278(.005)$ \\
\hline
\end{tabular}

Note. Z: $Z$ statistic based on the Mann-Whitney test; R: range (minimum-maximum), SE: standard error, $\chi^{2}$ : Statistical $\chi^{2}$ based on the Chi-Square test, $p$ : probability.

The nursing workload indicators showed differences in the patients with and without VAP only for some indicators (see Table 4). The patients with VAP show higher values of NAS-ad (median 59.70 versus 52.70), NAS-m (median 57.57 versus 52.93) indicating higher nursing workload; and showed lower values of NAS-paas (median $87.37 \%$ versus 94.74\%) indicating that for these patients the schedule is not associated with the nursing workload necessities. The increased workload in the admission and in the mean NAS value increased the risks or VAP acquisition $(\mathrm{OR}=1.12$ and $\mathrm{OR}=1.5$, respectively), while offering adequate schedule or nursing hours to patient care decreased the PAV acquisition risk $(\mathrm{OR}=0.86)$. Besides that, the patients without VAP showed higher values to NAS-i (median 1.40 versus 0 ) and NAS-ri (median 2.67 versus 0), indicating that patients with elevated increase in the NAS showed lower risks to VAP acquisition ( $\mathrm{OR}=0.93$ and $\mathrm{OR} 0.96$, respectively).

108
Some multivariate models were tested to predict VAP occurrence, as shown in Table 5. We proposed these models based on clinical application of the data. We proposed two models with all data from ICU stay. In model 1 (full model based on all the predictors for VAP occurrence during ICU stay), the risk predictors found for VAP were intubation occurs in days prior of the ICU admission day $(p=.022, \mathrm{OR}=11.60$, CI95\% $=1.41-95.23)$, the use of propofol $(p=.018$, OR $=$ 6.79$, CI95\% $=1.40-33.04)$, the presence of tracheostomy $(p=.009, \mathrm{OR}=9.58, \mathrm{CI} 95 \%=1.78-51.59)$ and ventilation time prior to ICU admission $(p=.015, \mathrm{OR}=.17, \mathrm{CI} 95 \%$ $=1.02-1.33$ ). In model 2 (reduced model based on all predictors for VAP occurrence during ICU stay) the predictors were intubation occurs in days prior of the ICU admission day $(p=.039, \mathrm{OR}=6.55, \mathrm{CI} 95 \%=1.10-39.89)$, the use of rocuronium bromide $(p=.015, \mathrm{OR}=70.51, \mathrm{CI} 95 \%=$ 2.28 -2177) the use of propofol $(p=.017, \mathrm{OR}=5.44, \mathrm{CI} 95 \%$

ISSN 1925-4040 E-ISSN 1925-4059 
$=1.35-21.83)$, the presence of tracheostomy $(p=.013, \mathrm{OR}=$ 5.79$, CI95\% $=1.44-23.22)$ and the ventilation time prior to ICU admission $(p=.009, \mathrm{OR}=1.16, \mathrm{CI} 95 \%=1.04-1.30)$. Only two predictors were found as protective to VAP occur- rence and were the NAS-paas $(p<.001, \mathrm{OR}=0.82, \mathrm{CI} 95 \%$ $=0.74-0.91)$ and the NAS-i $(p=.025, \mathrm{OR}=0.89, \mathrm{CI} 95 \%=$ $0.80-0.98)$.

Table 4. Univariate analysis of the nursing workload measurements based in NAS to predict the risk of VAP in an adult ICU

\begin{tabular}{|c|c|c|c|c|c|c|c|}
\hline \multirow{2}{*}{ Trait* } & \multicolumn{2}{|l|}{ without VAP } & \multicolumn{2}{|l|}{ with VAP } & \multirow{2}{*}{$Z(p)$} & \multicolumn{2}{|l|}{ Statistics } \\
\hline & Mean \pm SE & Median & Mean \pm SE & Median & & OR (LL-UL) & $p$ \\
\hline NAS-ad & $54.28 \pm 0.62$ & 52.70 & $62.25 \pm 1.25$ & 59.70 & $-5.73(<.001)$ & $1.12(1.07-1.17)$ & $<.001$ \\
\hline NAS-i & $4.02 \pm 0.74$ & 1.40 & $1.00 \pm 0.68$ & 0 & $-3.58(<.001)$ & $0.93(0.88-0.99)$ & .023 \\
\hline NAS-ri & $7.89 \pm 1.40$ & 2.67 & $1.96 \pm 1.11$ & 0 & $-3.69(<.001)$ & $0.96(0.93-0.99)$ & .016 \\
\hline NAS-m & $53.69 \pm 0.10$ & 52.93 & $60.39 \pm 1.07$ & 57.57 & $-5.53(<.001)$ & $1.15(1.09-1.21)$ & $<.001$ \\
\hline NAS-paas & $95.68 \pm 0.76$ & 94.74 & $85.01 \pm 1.31$ & 87.37 & $-6.21(<.001)$ & $0.86(0.81-0.9)$ & $<.001$ \\
\hline NAS-a & $9.01 \pm 0.91$ & 6.00 & $7.07 \pm 0.90$ & 6.50 & $-0.71(.481)$ & $0.98(0.94-1.01)$ & .224 \\
\hline NAS-cv & $5.16 \pm 0.40$ & 3.27 & $4.28 \pm 0.50$ & 4.14 & $-0.78(.436)$ & $0.95(0.89-1.03)$ & .227 \\
\hline NAS- $\Delta$ & $-0.83 \pm 0.54$ & 0 & $-2.31 \pm 0.94$ & 0 & $-1.33(.185)$ & $0.96(0.92-1.01)$ & .161 \\
\hline NAS-r $\Delta$ & $-0.97 \pm 0.97$ & 0 & $-3.06 \pm 1.44$ & 0 & $-1.21(.226)$ & $0.98(0.95-1.01)$ & .250 \\
\hline
\end{tabular}

*See Table 1 for traits description; Z: Z statistic based on the Mann-Whitney test; SE: standard error $p$ : probability, OR: Odds-Ratio, LL: lower limit of $95 \%$ confidence interval from OR, UL: upper limit of $95 \%$ confidence interval of OR.

We also proposed two models with data available at ICU admission or the first day in the ICU, since this predictor could easily show the future risk of VAP diagnosis and serve as guide to healthcare changes and preventive actions or treated in clinical case conduction of the patient. In model 3 (full model), the significant predictors of risk found for VAP were the intubation occurs in days prior of the ICU admission day $(p=.018, \mathrm{OR}=7.88, \mathrm{CI} 95 \%=1.41-43.95)$, ventilation time prior to ICU admission $(p<.001, \mathrm{OR}=1.30, \mathrm{CI} 95 \%=$ $1.14-1.47)$ and the NAS-ad $(p=.001, \mathrm{OR}=1.11, \mathrm{CI} 95 \%=$ 1.04-1.18). Finally, in model 4 (reduced model based on all predictors present at patient admission), the same predictors of model 3 were observed with the intubation occurs in days prior of the ICU admission day ( $p=.018, \mathrm{OR}=7.66, \mathrm{CI} 95 \%$ $=1.43-41.13)$, ventilation time prior to ICU admission $(p<$ $.001, \mathrm{OR}=1.30, \mathrm{CI} 95 \%=1.16-1.46)$ and the NAS-ad $(p=$ $.001, \mathrm{OR}=1.10, \mathrm{CI} 95 \%=1.04-1.16)$.

The models have good adjustments to the data. Model 1 presented R2 Nagelkerke of $81.4 \%$; with a probability of general accuracy of $93.3 \%$, accuracy for the occurrence of VAP of $84.9 \%$ and correct answers for the absence of VAP of $96.5 \%$. Model 2 presented R2 Nagelkerke of 78.2\%; with a probability of general accuracy of $90.8 \%$, accuracy for the occurrence of VAP of 79.2\% and correct answers for the absence of VAP of $95.1 \%$. Model 3 presented R2 Nagelkerke of $70.6 \%$; with a probability of general accuracy of $90.8 \%$, the occurrence of VAP of 75.5\% and correct answers for the absence of VAP of $96.5 \%$. Model 4 presented R2 Nagelkerke of $67.7 \%$; with a probability of general accuracy of $90.3 \%$, the occurrence of VAP of $77.4 \%$ and correct answers for the absence of VAP of $95.1 \%$.

\section{DISCUSSION}

The patient's profile in the study is similar, with no differences in severity scores and outcomes between the groups with and without VAP. However, patients diagnosed with hospitalization due to trauma had a higher incidence of VAP. The increase in the risk of VAP in these patients, especially those who presented severe trauma, is due to the fact that since trauma is an emergency and intubation is unplanned, time limited and is often performed in situations of high stress. Besides, this is an invasive procedure that compromises the lower respiratory tract defense barriers. Thus, there is a risk of non-performance of an adequate technique which, consequently, increases the risk factor for the development of VAP. In addition, this trauma patient profile is also subjected to several other invasive procedures and transportation in the emergency care that is not always adequate. ${ }^{[10,21]}$ Ventilatorassociated pneumonia is common in trauma patients but is independently associated with death in less severely injured trauma patients, and prevention of VAP in less severely injured trauma patients should increase survival. ${ }^{[22]}$ 
Table 5. Full and reduced multivariate models of prediction of risk of VAP in an adult ICU

\begin{tabular}{|c|c|c|c|c|c|c|}
\hline Model & Predictor & $\mathbf{B i}$ & $p$ & OR & $L L$ & $U L$ \\
\hline \multirow{18}{*}{$\begin{array}{l}\text { Full } \\
\text { ICU } \\
\text { Predictors }\end{array}$} & Intubation occurs in days prior of the day of admission in the ICU & 2.45 & .022 & 11.60 & 1.41 & 95.23 \\
\hline & Propofol use & 1.92 & .018 & 6.79 & 1.40 & 33.04 \\
\hline & Tracheostomy presence & 2.26 & .009 & 9.58 & 1.78 & 51.59 \\
\hline & Ventilation time prior to ICU (day) & 0.15 & .027 & 1.17 & 1.02 & 1.33 \\
\hline & Trauma hospitalization diagnosis & 1.33 & .130 & 3.76 & 0.68 & 20.93 \\
\hline & Rocuronium Bromide use & 4.31 & .123 & 74.25 & 0.31 & 17728 \\
\hline & Presence of invasive blood pressure & 0.75 & .313 & 2.12 & 0.49 & 9.10 \\
\hline & Presence of delayed bladder catheterization & 0.30 & .794 & 1.36 & 0.14 & 13.20 \\
\hline & Presence of coagulopathy & 0.53 & .585 & 1.70 & 0.25 & 11.32 \\
\hline & Corticosteroid use & 1.08 & .169 & 2.93 & 0.63 & 13.57 \\
\hline & Mean arterial pressure (value) & 0.01 & .547 & 1.01 & 0.97 & 1.06 \\
\hline & NAS-paas (\%) & -0.37 & .120 & 0.69 & 0.43 & 1.10 \\
\hline & NAS-m (points) & -0.24 & .495 & 0.78 & 0.39 & 1.58 \\
\hline & NAS-i (points) & -0.11 & .252 & 0.90 & 0.74 & 1.08 \\
\hline & NAS-ad (points) & 0.04 & .747 & 1.04 & 0.82 & 1.32 \\
\hline & Adherence to oral hygiene (\%) & 0.004 & .823 & 1.00 & 0.97 & 1.04 \\
\hline & Pneumothorax presence & 0.61 & .856 & 1.84 & 0.003 & 1308 \\
\hline & Constant & 36.14 & .363 & & & \\
\hline \multirow{8}{*}{$\begin{array}{l}\text { Reduced } \\
\text { ICU } \\
\text { Predictors }\end{array}$} & Intubation occurs in days prior of the day of admission in the ICU & 1.88 & .039 & 6.55 & 1.10 & 38.98 \\
\hline & Rocuronium Bromide use & 4.26 & .015 & 70.51 & 2.28 & 2177 \\
\hline & Propofol use & 1.69 & .017 & 5.44 & 1.35 & 21.83 \\
\hline & Tracheostomy presence & 1.76 & .013 & 5.79 & 1.44 & 23.22 \\
\hline & Ventilation time prior ICU (day) & 0.15 & .009 & 1.16 & 1.04 & 1.30 \\
\hline & NAS-paas (\%) & -0.20 & $<.001$ & 0.82 & 0.74 & 0.91 \\
\hline & NAS-i (points) & -0.12 & .025 & 0.89 & 0.80 & 0.98 \\
\hline & Constant & 13.38 & .004 & & & \\
\hline \multirow{8}{*}{$\begin{array}{l}\text { Full } \\
\text { Admission } \\
\text { Predictors }\end{array}$} & Intubation occurs in days prior of the day of admission in the ICU & 2.07 & .018 & 7.88 & 1.41 & 43.95 \\
\hline & Ventilation time prior ICU (day) & 0.26 & $<.001$ & 1.30 & 1.14 & 1.47 \\
\hline & NAS-ad (points) & 0.11 & .001 & 1.11 & 1.04 & 1.18 \\
\hline & Trauma hospitalization diagnosis & 0.89 & .155 & 2.44 & 0.71 & 8.38 \\
\hline & Presence of invasive blood pressure & 0.84 & .142 & 2.32 & 0.76 & 7.10 \\
\hline & Mean arterial Pressure (value) & 0.01 & .565 & 1.01 & 0.98 & 1.04 \\
\hline & Sex (1: Female) & -0.78 & 199 & 0.46 & 0.14 & 1.50 \\
\hline & Constant & -11.15 & $<.001$ & & & \\
\hline \multirow{4}{*}{$\begin{array}{l}\text { Reduced } \\
\text { Admission } \\
\text { Predictors }\end{array}$} & Intubation occurs in days prior of the day of admission in the ICU & 2.04 & .018 & 7.66 & 1.43 & 41.13 \\
\hline & Ventilation time prior ICU (day) & 0.26 & $<.001$ & 1.30 & 1.16 & 1.46 \\
\hline & NAS-ad (points) & 0.09 & .001 & 1.10 & 1.04 & 1.16 \\
\hline & Constant & -9.02 & $<.001$ & & & \\
\hline
\end{tabular}

Note. Bi: i-th coefficient estimative from the model parameters; OR: Odds-Ratio, $L L$ : lower limit of 95\% confidence interval from OR, UL: upper limit of $95 \%$ confidence interval of $O R$; $p$ : probability associated to the parameter estimative. 
A significant increase in total hospitalization costs was also observed in the group of patients with VAP, which corroborates the increase in hospital costs for patients with HAI. In this sense, it is important to highlight that a study showed that HAI in ICU was associated to doubling of the total cost of hospitalization when compared to patients who did not develop HAI during hospitalization. ${ }^{[23]}$ A study showed that patients with VAP had significantly longer hospital stays with 21 days versus 11 days $(p<.0001)$ and incurred in higher hospital costs, US\$ 6,250.92 against US\$ 2,598.84 $(p<.0001) ;{ }^{[24]}$ which corroborates our results. Another study found similar results and showed that the mean cost of hospitalization was US\$ 99,598 for patients with VAP and US\$59,770 for patients without VAP, resulting in an absolute difference of US\$39,828. ${ }^{[25]}$ The mean cost of antibiotic use per patient was US\$1,514.79 for the same ICU studied here in the other study, where patients with HAI were evaluated. ${ }^{[26]}$ Although these studies are not comparable by as the baselines are not equals and the hospital adopted different staffing models and healthcare activities are likely to be different, they reinforce the findings that the presence of HAI (including VAP) increases hospital stay time and costs.

Another multicenter study, conducted at nine hospitals in Europe, showed that in an attempt to reduce costs, nursing staff cuts were made, consequently decreasing the offer of nursing workload. This led to worse patient outcomes and, ironically, cost increases. ${ }^{[27]}$ In this sense, the present study showed that the nursing workload can influence the incidence of VAP and consequently hospital costs. In this sense, the evidence is increasing that the nursing workload is as a predictive variable to infection, adverse events and costs and other outcome variables in healthcare that could indirectly lead to higher costs for hospitals. ${ }^{[28,29]}$ Since the public health system in Brazil pays hospital costs as a function of hospitalization time, specialized activities and type of unit, the impact of VAP on hospitalization time (about 14 days more in the infirmary and hospital), the impact of VAP on hospitalization time is perhaps the most important factor in cost assessment since the measurement of the real costs in public services is difficult.

In all the multivariate models tested by us, the predictive variables to VAP occurrence were intubation the previous day of ICU admission and the time of ventilation before ICU admission. The two risk factors demonstrated that the way healthcare is provided before ICU admission can directly interfere in the risk of VAP in the ICU. Specifically to nursing, it is inferred, therefore, that the nursing staff was reduced in the hospitalization units when compared to the number of professionals in the ICU, which demonstrates that when the adequacy of sizing is not possible, it can lead to an in-

Published by Sciedu Press crease in number of adverse events, such as VAP. ${ }^{[30]}$ In the hospital studied here, the emergency room had a deficit and a necessity of increase of $51.63 \%$ in nursing staff, compared to $28.86 \%$ increase in ICU; evidencing the reduced staff in initial hospital admission. ${ }^{[19]}$ In addition, in some units of the hospital of which ICU patients originate, they presented low adequacy in the number of nursing professionals dedicated to patient care. ${ }^{[19]}$ Probably the low nursing training related to patient healthcare also could explain the effects of ventilation time in these units, leading to an increase in the risk of VAP. ${ }^{[19]}$ Similar results were found for other HAI in the same ICU studied here, where insertion of the central venous catheters outside the ICU increased the chances of infection in the subclavian and jugular routes (OR: 2.25 and 0.27); and the chances of infection in the jugular route increased with tracheostomy presence (OR: 3.83). ${ }^{[31]}$ Additional studies are necessary to try to explain the factors related to higher risk in these patients mainly related to patient care before admission in the ICU.

Other studies show that the impact of location of intubation in predicting the risk of VAP could be discrepant in trauma patients comparing prehospital and trauma room intubation, and some cases are significant only when other variables are included in the models, as chest injury (crude OR $1.16 p=$ .600 , adjusted OR $0.17, p<.003) \cdot{ }^{[32]}$

In the univariate analysis, the measurements of NAS show good capacity to predict the occurrence of VAP. The NASad, NAS-i, NAS-ri, NAS-m and NAS-paas were associated of VAP occurrence. The NAS-ad, NAS-m show that high demand for nursing care is a predictive factor of VAP, reinforced by the NAS-paas, since the high values where the schedule is adequate reduce the risks of VAP. Offering an adequate number of nursing professionals is an excellent form of reducing the chances of VAP, probably because of the adequate execution of technical care related to intubation and ventilator state. We were not able to say what care measured by NAS is associated with VAP by not registering NAS sub-items in the medical charts or forms, which should be included in future studies.

We observed a increasing of 6.7 points or 96.48 minutes in NAS based in mean of NAS or an increase of 4.64 points or 66.82 minutes based in median of NAS. As the study was retrospective, it was not possible to obtain which NAS sub-items suffered additions due to VAP, since there are no records of the subitems in the records. Offering adequate nursing hours of care during all ICU stays proved to be necessary to prevent VAP, since the study demonstrates that nurses estimated that the standard ventilator bundle requires a median of 115 min per patient per day, although the majority 
of nurses did not perceive that other patient care tasks were delayed. ${ }^{[33]}$

The publics, federatives and Brazilian hospitals following the legislation to scale the nursing professionals, following in the ratio of two patients to each professional. Even knowing the workload or scientific evidences that demonstrate improvement in patient outcomes by providing better healthcare (in the case studied here offer more professionals to care from patients), public institutions are unable to change this situation (two patients to each nursing professional). The institutions have no autonomy to hire professionals from any area, once there is a need for the government's consent. However, studies such as the presented here can support the request for vacancies by nursing professionals, and together with the increase in workload studies and better scientific evidences, together can support the construction of public policies that determine a better allocation of professionals in hospital units. Brazilian literature is still lacking in studies that measure the impact of the patient's clinical profile on the nursing workload and even other professionals.

In the two multivariate models presented in admission in the ICU and in the univariate model, it is verified that the NAS of admission (NAS-ad) is a predictor of VAP, that is, the higher the workload required at admission, the higher the risk of VAP. Patients with high NAS in admission probably require the attention from the team that could be planning better healthcare.

In the reduced model of ICU stay, the percentage of adequacy of the assignment (NAS-paas), showed that the more appropriate the work schedule measured by the NAS, the lower the risk of VAP. It also showed that the higher the increase in NAS (NAS-i) in relation to admission, the lower the risk of VAP. The hypothesis for this fact is that larger increments alert the team, which facilitates adjustment of the schedules and of healthcare. However, this situation does not occur with minimal changes, which may go unnoticed by the team. The compliance with preventive VAP actions in patients with low nursing workload measured by the Nursing Activites Score was lower compared to patients with higher levels of nursing workload. ${ }^{[34]}$

The results of this research are in line with results verified in other studies. ${ }^{[30,34-36]}$ In one of these studies, carried out with 195 patients, 43 (22\%) developed HAI and, as in the present study, an excessive nursing workload was identified as a risk factor for HAI (OR: 11.41; p .019). ${ }^{[30]}$ A metaanalysis, which included 38 studies, showed that in only 7 (18\%) of the cases studied, it was not possible to observe a statistically significant relationship between variables that measure nursing team size and HAI rates. ${ }^{[35]}$ In another study, a high positive correlation was also found between workload variables and the rate of adverse events. ${ }^{[36]}$

The use of sedatives as propofol as well as neuromuscular blockers, whose utilization is quite common in the ICUs, is also verified as predictors for VAP. Such drugs are known to have several immunomodulatory effects on de-fense cells, and in vitro studies have shown that high concentrations of propofol may interfere with human neutrophil functions such as chemotaxis and phagocytosis, suggesting a greater risk for infection. ${ }^{[37,38]}$

The tracheostomy presence was also a risk factor for VAP. This finding is still contradictory in the literature since some studies suggest that tracheostomy would reduce the incidence of VAP by facilitating bronchial lavage and weaning from mechanical ventilation. On the other hand, other studies relate tracheostomy to the longer period of me-chanical ventilation, as well as longer ICU stay, leading to a higher risk of acquiring other infections. ${ }^{[37-43]}$

We have no assumption that nursing workload is the unique contributor related to nursing for the results of any patient outcomes. Other aspects related to nursing such as team qualification, degree of training, level of knowledge, form of work and the impact of students in educational institutions can interfere with patient's outcomes. Unfortunately, in retrospective studies such as our, these variables are difficult to evaluate by the low records of this data. Future and prospective studies could consider these and other aspects related to workload from professionals.

\section{Conclusion}

The present study allowed us to conclude that the total cost of hospitalization is higher in the group with VAP mainly related to longer hospital stay time. The risk of VAP increases in patients who were intubated before the day of admission in the ICU, tracheostomized, had used a neuromuscular blocker, had used propofol, had higher time of mechanical ventilation in pre-admission in the ICU, and higher NAS admission. Patients requiring higher measured nursing workload in admission in ICU (higher NAS-ad) show higher risks of VAP. Also patients with higher increment in NAS during mechanical ventilation in ICU and higher Percentage of Adequacy of the assignment based in NAS (NAS-paas) that measure if the workload measured by NAS was offered in the ICU (if $100 \%$ all workload measured was offered in the ICU) show lower risk of VAP. The NAS and their derivate metrics were effective in showing the relation between nursing workload and suitability in the design and the reduction of VAP. 


\section{ACKNOWLEDGEMENTS}

We would like to thank the entire Intensive Care Unit team at the Universidade Federal de Uberlândia for support during the study. The study was part of the PhD of the first author in the Post-graduation Program in Health Sciences, Federal
University of Uberlândia.

\section{CONFLicts OF INTEREST Disclosure}

The authors declare that there is no conflict of interest.

\section{REFERENCES}

[1] Cilloniz C, Martin-Loeches I, Garcia-Vidal C, et al. Microbial etiology of pneumonia: epidemiology, diagnosis and resistance patterns. Int J Mol Sci. 2016; 17(12): E2120. PMid:27999274 https://doi.org/10.3390/ijms17122120

[2] Teixeira PJZ, Hertz FT, Cruz DB, et al. Pneumonia associada à ventilação mecânica: impacto da multirresistência bacteriana na morbidade e mortalidade. J Bras Pneumol. 2004; 30(6): 540-548. https://doi.org/10.1590/S1806-37132004000600009

[3] Rocha LA, Vilela CA, Cezário RC, et al. Ventilator-associated pneumonia in an adult clini-cal-surgical intensive care unit of Brazilian university hospital: incidence, risk factors, etiology, and antibiotic re-sistance. Braz J Infect Dis. 2008; 12(1): 80-85. PMid:18553020 https://doi.org/10.1590/S1413-86702008000100017

[4] Rello J, Allegri C, Rodriguez A, et al. Risk factors for ventilatorassociated pneumonia by Pseudomonas aeruginosa in presence of recent antibiotic exposure. Anesthesiology. 2006; 105: 709-714. PMid:17006069 https ://doi.org/10.1097/00000542-20061 0000-00016

[5] Chacko B, Thomas K, David T, et al. Attributable cost of a nosocomial infection in the intensive care unit: A prospective cohort study. World J Crit Care Med. 2017; 6(1): 79-84. PMid:28224111 https://doi.org/10.5492/wjccm.v6.i1.79

[6] Zimichman E, Henderson D, Tamier O, et al. Health-care associated infections. A meta-analysis of costs and finan-cial impact on US healthcare system. JAMA. 2013; 173(22): 2039-46. PMid:23999949 https://doi.org/10.1001/jamainternmed. 2013.9763

[7] McGahan M, Kucharski G, Coyer F. Nurse staffing levels and the incidence of mortality and morbidity in the adult intensive care unit: a literature review. Aust Crit Care. 2012; 25(2): 64-77. PMid:22515951 https://doi.org/10.1016/j.aucc. 2012.03.003

[8] Hugonnet S, Uckay I, Pittet D. Staffing level: a determinant of lateonset ventilator-associated pneumonia. Crit Care. 2007; 11(4): R80. PMid:17640384 https://doi.org/10.1186/cc5974

[9] Oliveira AC, Garcia PC, Nogueira LS. Nursing workload and occurrence of adverse events in intensive care: a sys-tematic review. Rev Esc Enferm USP. 2016; 50(4): 679-689. PMid:27680056 https://doi.org/10.1590/S0080-623420160000500020

[10] Needleman J, Buerhaus P, Mattke S, et al. Nurse Staffing levels and the quality of care in hospitals. N Engl J Med. 2002; 346(22): 17151722. PMid:12037152 https://doi .org/10.1056/NEJMsa0122 47

[11] Aiken LH, Sloane DM, Bruyneel L, et al. Nurse Staffing and education and hospital mortality in nine European countries: a retrospective observational study. Lancet, 2014; 383(9931): 18241830. PMid:24581683 https://doi.org/10.1016/S0140-673 6(13) 62631-8

[12] Neuraz A, Guérin C, Payet C, et al. Patient mortality is associated with staff resources and workload in the ICU: A multicenter observational study. Crit Care Med. 2015; 43(8): 1587-94. PMid:25867907 https://doi.org/10.1097/CCM.0000000000001015
[13] Kraljic S, Zuvic M, Desa K, et al. Evaluation of nurses' workload in intensive care unit of a tertiary care university hospital in relation to the patients' severity of illness: A prospective study. Int J Nurs Stud. 2017; 13(76): 100-105. PMid:28950187 https : //doi.org/10.1016/j.ijnurstu.2017.09.004

[14] Novaretti MC, Santos EV, Quitério LM, et al. Sobrecarga de trabalho da Enfermagem e incidentes e eventos adversos em pacientes internados em UTI. Rev Bras Enferm. 2014; 67(5): 692-699. PMid:25517661 https://doi.org/10.1590/0034-7167.2014 670504

[15] Queijo AF, Padilha KG. Nursing Activities Score (NAS): adaptação transcultural e validação para a língua portuguesa. Revi Esc Enferm USP. 2009; 43: 1018-1025. https ://doi .org/10.1590/s0 080-62342009000500004

[16] Miranda DR, Nap R, de Rijk A, et al. TISS Working Group. Therapeutic Intervention Scoring System. Nursing activities score. Crit Care Med. 2003; 31(2): 374-382. PMid:12576939 https://doi. org/10.1097/01. CCM. 0000045567.78801. CC

[17] American Thoracic Society; Infectious Diseases Society of America. Guidelines for the management of adults with hospital-acquired, ventilator-associated, and healthcare-associated pneumonia. Am J Respir Crit Care Med. 2005; 171(4): 388-416. PMid:15699079 https://doi.org/10.1164/rccm.200405-644ST

[18] Mendes-Rodrigues C, Costa KES, Antunes AV, et al. Carga de trabalho e dimensionamento de pessoal de enfermagem em unidades de terapia intensiva. Rev Aten Saúde. 2017; 15(53): 5-13. https : //doi.org/10.13037/ras.vol15n53.4159

[19] Mendes-Rodrigues C, Antunes AV, Mendonça GS, et al. Quality indicators applied in a nursing continuing education program of a high complexity University Hospital from Brazil: IV - Training indicator versus sizing and workload. Biosci J. 2018; 34(2): 465-476.

[20] Brasil. Ministério da Saúde; Conselho Nacional de Saúde. Resolução n. 466, de 12 de dezembro de 2012. Dispõe sobre as diretrizes e normas regulamentadoras de pesquisas envolvendo seres humanos [Internet]. Brasília; 2012 [cited 2015 jan. 11]. Available from: http: //conselho.saude.gov.br/resolucoes/2012/Reso466.pdf

[21] Gupta R, Malik A, Rizvi M, et al. Epidemiology of multidrugresistant Gram-negative pathogens isolated from ventilator-associated pneumonia in ICU patients. J Glob Antimicrob Resist. 2017; 9: 4750. PMid:28288860 https://doi .org/10.1016/j.jgar. 2016. 12.016

[22] Magnotti LJ, Croce MA, Fabian TC. Is Ventilator-Associated Pneumonia in Trauma Patients an Epiphenomenon or a Cause of Death? Surg Infect. 2004; 5(3): 237-242. PMid:15684794 https://doi. org/10.1089/sur. 2004.5.237

[23] Gilstrap D, Davies J. Patient-Ventilator interactions. Clin Chest Med; 2016; 37(4): 669-681. PMid:27842747 https://doi.org/10.1 016/j.ccm.2016.07.007

[24] Mathai AS, Phillips A, Kaur P, et al. Incidence and attributable costs of ventilator-associated pneumonia (VAP) in a tertiary-level intensive care unit (ICU) in northern India. J Infect Public Health. 2015; 
8(2): 127-135. PMid:25444392 https://doi.org/10.1016/j. jiph.2014.07.005

[25] Kollef MH, Hamilton CW, Ernst FR. Economic impact of ventilatorassociated pneumonia in a large matched cohort. Infect Control Hosp Epidemiol. 2012; 33(3): 250-256. PMid:22314062 https: //doi.org/10.1086/664049

[26] Lara FLO, Antunes AV, Mendes-Rodrigues C, et al. Custos da antibioticoterapia em pacientes adultos com infecção hospitalar em uma unidade de terapia intensiva. Rev Pre Infec e Saúde. 2017; 3(4): 8-14. https://doi.org/10.26694/repis.v3i4.6621

[27] Medell M, Hart M, Marrero O, et al. Clinical and microbiological characteriza-tion of pneumonia in mechanically ventilated patients. Braz J Infect Dis. 2012; 16: 442-447. PMid:22975167 https://doi.org/10.1016/j.bjid.2012.08.005

[28] Nogueira TDA, Menegueti MG, Perdoná GDSC, et al. Effect of nursing care hours on the outcomes of intensive care assistance. Plos One 2017; 12(11): e0188241. PMid:29190742 https ://doi.org/10 .1371/journal.pone. 0188241

[29] Stafseth SK, Tønnessen TI, Fagerström L. Association between patient classification systems and nurse staffing costs in intensive care units: An exploratory study. Intensive Crit Care Nurs. 2018; 45: 7884. PMid:29402682 https://doi.org/10.1016/j.iccn. 2018. 01.007

[30] Daud-Gallotti RM, Costa SF, Guimarães T, et al. Nursing workload as a risk factor for healthcare associated infections in ICU: a prospective study. PLoS One. 2012; 7(12): e52342. PMid:23300645 https://doi.org/10.1371/journal . pone. 0052342

[31] Silva RF, Mendes-Rodrigues C, Pereira EBS, et al. Risk factors for bloodstream infection and influence on mortality rate. Rev Pre Infec e Saúde. 2017; 3(3): 9-20. https://doi.org/10.26694/repis .v3i3.6476

[32] Arumugam SK, Mudali I, Strandvik G, et al. Risk factors for ventilator-associated pneumonia in trauma patients: A descriptive analysis. World J Emerg Med. 2018; 9(3): 203210. PMid:29796145 https://doi.org/10.5847/wjem.j.192 0-8642.2018.03.007

[33] Branch-Elliman W, Wright SB, Gillis JM, et al. Estimated nursing workload for the implementation of ventilator bundles. BMJ Qual Saf. 2013; 22(4): 357-361. PMid:23431219 https ://doi .org/10 $.1136 /$ bmjqs-2012-001372

[34] Jam R, Mesquida J, Hernández Ó, et al. Nursing workload and compliance with non-pharmacological measures to prevent ventilator- associated pneumonia: a multicentre study. Nurs Crit Care. 2018; 23(6): 291-298. PMid: 30182383 https://doi.org/10.1111/ nicc. 12380

[35] Stone PW, Pogorzelska M, Kunches L, Hirschhorn LR. Hospital staffing and health care-associated infections: a systematic review of the literature. Clin Infect Dis. 2008; 47(7): 937-944. PMid:18767987 https://doi.org/10.1086/591696

[36] Carlesi KC, Padilha KG, Tofoletto MC, et al. Patient safety incidents and nursing work-load. Rev. Latino-Am. Enfermagem. 2017; 25: e2841. PMid: 28403334 https://doi.org/10.1590/1518-834 5.1280 .2841

[37] Caroff DA, Szumita PM, Klompas M. The relationship between sedatives, sedative strategy, and healthcare-associated infection: A Systematic Review. Infect Control Hosp Epidemiol. 2016; 37(10): 1234-42. https://doi.org/10.1017/ice.2016.129

[38] Smith MA, Hibino M, Falcione BA, et al. Immunosuppressive aspects of analgesics and sedatives used in mechanically ventilated patients: An underappreciated risk factor for the development of ventilator-associated pneumonia in critically ill patients. Ann Pharmacother. 2014; 48(1): 77-85. PMid: 24259637 https : //doi.org/10.1177/1060028013510698

[39] Frutos-Vivar F, Esteban A, Apezteguía C, et al. International Mechanical Ventilation Study Group. Outcome of mechanically ventilated patients who require a tracheostomy. Crit Care Med. 2005; 33(2): 290-298. https://doi.org/10.1097/01.CCM. 0000150026.85 210.13

[40] Warren DK, Shukla SJ, Olsen MA, et al. Outcome and attributable cost of ventilator-associated pneumonia among intensive care unit patients in a suburban medical center. Crit Care Med. 2003; 31: 13121317. PMid:12771596 https://doi.org/10.1097/01. CCM. 000 0063087.93157 .06

[41] Wright SE, VanDahm K. Long-term care of the tracheostomy patient. Clin Chest Med. 2003; 24: 473-487. https://doi.org/10.1016/ S0272-5231 (03) 00054-6

[42] Aranha SC, Mataloun SE, Moock M, et al. Estudo comparativo entre traqueostomia precoce e tardia em pacientes sob ventilação mecânica. Rev Bras Ter Intensiva. 2007; 19(4): 444-449. https: //doi.org/10.1590/S0103-507X2007000400007

[43] Raimondi N, Vial MR, Calleja J, et al. Evidence-based guidelines for the use of tracheostomy in critically ill patients. J Crit Care. 2017; 38: 304-318. PMid:28103536 https://doi.org/10.1016/j.jc rc.2016.10.009 